\title{
PREFACE \\ Urban Political Development and the Politics of Ideas
}

\author{
Robert Henry Cox and Daniel Béland
}

Constructivist social scientists take it as self-evident that human societies are constructed by the people who inhabit them. The physical world does not prescribe a particular way that any society should be ordered, its order coming instead from the choices made by the people who comprise these societies.

Cities are also historically and socially constructed, not natural creations. This is the basic message of this volume and makes a compelling case for the value of a constructivist approach to understanding urban political development. At a time when constructivism is growing across the social sciences, Richardson Dilworth, Timothy P. R. Weaver, and the other contributors to this volume have made a strong case for understanding why ideas have been the real drivers behind urban political development and why a constructivist understanding is more persuasive than conventional approaches.

What distinguishes constructivist from conventional approaches is that these approaches see the social world as analogous to the natural world, therefore requiring the same manner of investigation to reveal its secrets. Constructivists, by contrast, assume that a big difference between the natural and the social world is that human beings shape their social orders by imbuing them with meaning. There are physical and biological elements to any social order. Families have biological relationships; safety and security can be enhanced by living in close proximity; and we have the ability to construct durable shelter. All these things we can investigate using conventional methods of analysis.

An urban space can be described in terms of its physical characteristics, but it also has a meaning to the people who inhabit it. Open plazas can be spaces 
for relaxation and contemplation or for commerce and exchange. Some buildings can provide spaces for various rituals, ranging from spiritual to hygienic. The buildings can be described in terms of their physical characteristics and the functional needs they serve, but the description is incomplete without also explicating their meanings to the actors who built and inhabited them.

Explicating the meaning and significance of social spaces requires allowing actors to speak about their own subjective meanings. This in turn requires that researchers appreciate those subjective meanings as being constitutive of the social order they wish to understand. Conventional approaches take the opposite approach. In a conventional inquiry, the investigator begins by defining terms, looking for evidence of those terms, and refining her or his understanding following a test of the terms in situ. All the thinking and acting is done by the researcher.

The approach advocated in this volume, by contrast, is to not construct a priori definitions of terms, preferring instead to embrace the ideas-and the meanings they evoke-as they are used by the actors themselves. The objective is to reveal how humans think and reason about the urban spaces they create.

Another important difference is that constructivists are concerned with shared meanings. It matters to know what a key decision maker thinks, but it also matters to know what ideas have resonance with a broader group of people. Understandings of the world, like cities themselves, are built by people who create and reproduce common meanings for their surroundings. For conventional views, by contrast, the meaning that matters is the one constructed by a solitary researcher who devises his terms and outlines the relationships among them. The conventional researcher seeks conceptual precision, theoretical elegance, and simplicity of causes. Constructivists, by contrast, assume that the world is a messier place and seek to explain how humans strive to navigate and make sense of its complexity. Needless to say, we get much richer and more textured understanding from a constructivist approach.

We see this point illustrated when we consider the role of interests in social science research. As the editors of this volume point out, the notions of interests are dominant in depictions of how actors influence urban development. But the concept of interest often employed by conventional scholars of urban political development is one that is devised by the researcher and ascribed to the actors. Indeed, the only way we could say that people act against their own interests is by having a notion of their interest that is independent of what they think themselves. A constructivist, on the other hand, 
takes it as a given that people act in their own interests (if that is what they say they are doing) but then seeks to explore why they define their interests in the way they do. The key issue is to find out what their interests are to them, not to compare them to some objective standard of interest.

This remark does not mean that interests are purely subjective or unrelated to material and institutional factors. What it means is that actors define their interests by interpreting their surroundings in certain ways, which might be grounded in particular historical and cultural meanings. From a constructivist standpoint, in other words, interests are complex and changing and do more than simply reflect the seemingly objective economic status of actors.

The same can be said for institutions. For the past thirty years, institutional analyses have been pervasive across the social sciences. Institutions are most commonly formulated as constraints; obstacles that savvy actors learn to maneuver around as they pursue their interests. Institutions are furthermore assumed to provide stability, forcing actions to follow a logic of incremental adjustment and preventing dramatic departures from the status quo. Institutions make change difficult. However, institutionalists recognize that change does happen, though they include it in their models as exogenous forces or shocks, such as unforeseen events.

Constructivists take a different view of institutions. Yes, institutions are stable forces that discourage dramatic change and lend predictability to social outcomes. And yes, they can be disrupted by exogenous forces. But they also can be disrupted by autonomous actors who envision alternatives to the status quo. For a constructivist, institutions matter until they don't. The purpose of research is not to prove the constraining force of institutions but instead to identify when institutions exercise this power and when actors decide to change their institutions. Institutional stability and change are treated as an empirical question, not a theoretical assumption.

Both interests and institutions, like cities, are constructed by human actors. Consequently, they too are inspired by the ideas held important by those actors. This is what we mean by the power of ideas. The real drivers of social change are ideas about how the world works. These ideas are generated by creative individual and collective actors, and influential actors can realize their ideas through their actions. Their ideas can form their interests and also inspire their efforts to build new or transform existing institutions. These are formulations that make the ideas more permanent and help to disseminate those ideas more broadly. Consequently, we can see in interests and institutions the ideas that inspired their architects. 
This point is illustrated by focusing on many of the ideas detailed in the empirical chapters of this volume. Blight, urban renewal, and urban crisis, to name a few, are ideas developed by specific actors to advocate certain courses of action. They describe discomfort with the status quo and frame the problem they identify. Their ideas are more successful when they are formulated in such a way as to generate broad appeal. In doing so, they give dimension to vague feelings that others might also have but had not found the ideas to express. Thus, ideas are more successful when they are formulated in such a way as to appeal to shared understandings of the world.

The shared meanings evoked by ideas are fluid. They often lack precise definition. This is why, as Sally Ford Lawton points out in Chapter 3, the idea of blight evokes a common sense of an undesirable state of affairs, but its imprecision allows actors to attach it to many different situations, some of which may not fit a technical or legal definition.

This fluidity of an idea opens it to contest over its relevance. Actors can debate whether the idea describes the situation accurately and whether it is defined correctly by the person invoking it. Such contests over the meanings of ideas and the situations to which they apply are at the heart of politics. Considered in this light, politics is more than the contest over who gets what, when and how, as Harold Lasswell famously put it. Politics is also about what is just, fair, and legitimate.

Clearly, ideas are an integral part of political battles, and different types of actors deploy these ideas to define and advance their cause. For example, in Chapter 4, Marcus Anthony Hunter shows how activists in Philadelphia used ideas to frame their opposition to the proposed Crosstown Expressway that threatened their communities. Conversely, in Chapter 11, Timothy P. R. Weaver focuses on the role of policy entrepreneurs in promoting the idea of enterprise zones in the United States and the United Kingdom. Here the focus is not on grassroots activists but instead is on experts and ideologues who try to sell their policy ideas to both business and government officials. What these two examples suggest is that within the politics of ideas, many different actors can move to the front stage to wage ideational battles over urban policy.

Another lesson from this volume is that the constructivist perspective associated with the study of the role of ideas in politics applies equally well to advanced industrial societies and to countries located in the Global South. The presence of case studies about Chile, China, India, and Africa in this volume is important because it shows how the constructivist perspective is applicable to different parts of the world and how domestic and transnational 
processes may interact. For instance, this interaction is central to Chapter 15, in which Vanessa Watson examines how urban design ideas from other parts of the world are adapted to African urban settings.

Finally, this volume offers historical perspectives that allow us to grasp the development and spread of ideas over time and their interaction with changing economic and political landscapes, including perceived crises, that may disrupt the status quo to various degrees, thus increasing the potential influence of new ideas. Taking into account these crises and variations enriches our understanding of both urban political development and the role of ideas in politics and public policy.

The authors of the chapters in this volume recognize the multifaceted and historically constructed character of urban politics and embrace it as an effort to bring meaning to the urban spaces we inhabit and the political struggles we witness and take part in. The contribution they make is not only to apply a focus on ideas to the study of urban political development but also to show us how our cities have been shaped and reshaped by the ideas that we and others have about what matters and how we wish to live together. More broadly, this volume considerably enriches our empirical and analytical knowledge of the politics of ideas more generally, something that could inspire constructivist social scientists who are located in other research areas. Because ideas are central to politics in general, the chapters of this volume contribute to our broader understanding of politics as much as to our knowledge of the more specific topic of urban political development, which illustrates perfectly why social scientists must pay close attention to ideas in their research about politics and public policy. 
